\title{
Automatic water level control using LabVIEW
}

\author{
Hemin Ismael Azeez \\ Communication Engineering Department \\ Technical college of Engineering \\ Sulaimani Polytechnic University \\ Sulaimani, Iraq \\ hemin.azeez@spu.edu.iq
}

\author{
Narongrit Pimkumwong \\ Electrical Engineering Department \\ Southern Taiwan University of Science \\ and Technology \\ Tainan, Taiwan \\ da42b204@ stust.edu.tw
}

\author{
Shih-Chung Chen \\ Electrical Engineering Department \\ Southern Taiwan University of Science and \\ Technology \\ Tainan, Taiwan \\ chung@mail.stust.edu.tw
}

\begin{abstract}
Shortage in water supply is one of the major issues that some major cities throughout the world are facing nowadays. Due to not having full day water supply, households will have to efficiently manage the problem of water shortage and overcome the crises. This paper presents a system that indicates and controls the level of water in overhead tanks. Ultra-sonic sensors are employed to detect the level of the water between predefined minimum and maximum levels. LabVIEW which is a graphical programming language that uses a dataflow model is used to program microcontroller board Arduino UNO that is an interface between the software and the rest of the circuit components. From measured results good performance and accurate results are achieved.
\end{abstract}

Keywords: LabVIEW, microcontroller, absolute error.

\section{INTRODUCTION}

Dwindling water supplies will affect city citizens and exacerbate conflict in the cities throughout the world. Due to not having full day water supply and besides public response to water conservation regulations, households need to think of effective solutions like installing water reservoir tanks down the floor and overhead tanks to efficiently manage the problem of water shortage and overcome the crises. In this regard, water pumps are being used to pump up water from the down water tank to the overhead tank.

The main purpose of this research is to use LabVIEW to control Arduino UNO board to automate the water level in an overhead tank and indicating the level of the water. Ultrasonic sensors are used as an alternative to conductors as a sensor based on distance measurement of the water surface from the predefined minimum and maximum levels and more importantly the water level is continuously detected.

\section{LITERATURE REVIEW}

Variety of controlling systems are introduced in [1][4] to overcome the problem and to automatically pump up and control the water level in the overhead tank.
In [1] a microcontroller based automatic water level control system using AT89C52 microcontroller is introduced. Authors in [2] have addressed the problem and presented a system of an automatic water level controller with SMS notification. Arduino UNO is also employed as controller system as it has an open source libraries. For the SMS circuit Motorola c261 model supports serial communication with headset plug has been employed that can support AT commands which can be used for Global System for Mobile (GSM) control system.

In addition, authors in [3] an automatic water level controller is developed and implemented. Arduino Uno has been chosen to automate the process of water pumping. Water level detection in both source and overhead tanks, switch on/off the pump accordingly are the main controlling signals the circuit. Liquid Crystal Display (LCD) display is used to show important data. Moreover, a microcontroller based automated water level sensing and controlling is proposed that covers both design and implementation issues[4]. PIC 16F84A microcontroller which is a family of RISC microcontrollers made by Microchip Technology is used and integrated to the circuit. It is worth mentioning that throughout these literatures, context of electrical conductivity of the water is used to employ copper and aluminium conductors as water detecting sensors and only discrete levels of the water are detected.

\section{SYSTEM MODEL AND DESCRIPTION}

The overall scope of the project is presented in Figure 1. The proposed system is composed of down and overhead water tanks, a pump to pump up water from down reservoir to the overhead tank. The Arduino UNO board operates based on the program written in LabVIEW will detect the water level via ultrasonic sensors as well as instructs the relay circuit when predefined water level limitations reached.

The whole process and control signalling are exchanged in a wired environment. To protect the water pump from working when there is no water in the down reservoir, to be cost effective extra sensors are not used in the down reservoir but the Arduino UNO board is programed in a way if there is no increment in the water 
level, the relay circuit will be instructed to turn off the are used to make the prototype are described below. water pump. The detail of the system components that

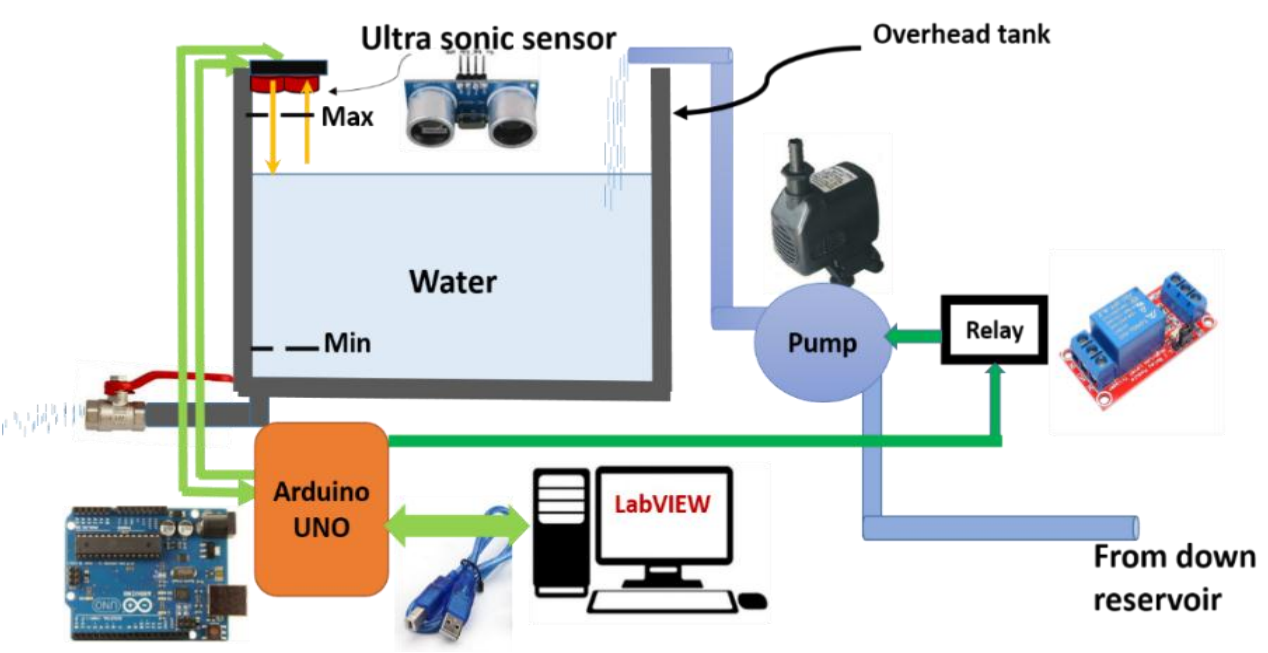

Figure 1Over all block diagram of the proposed system

\section{SYSTEM SCHEMATIC DIAGRAM}

The schematic diagram of the system is shown in figure 2 .

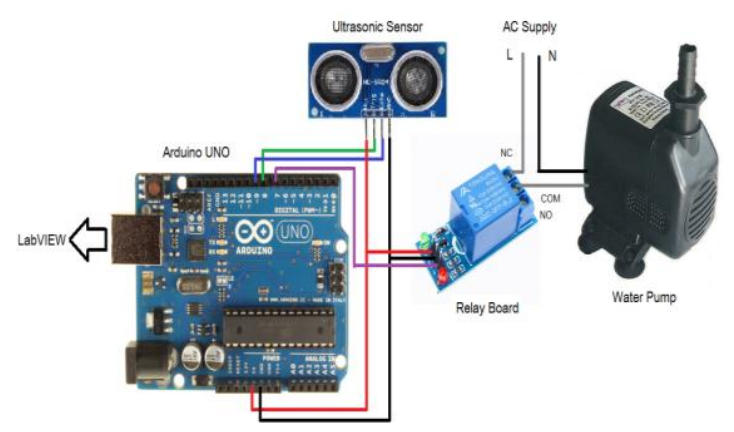

Figure 2Schematic diagram of the system

\subsection{Ultrasonic Sensor:}

The ultrasonic ranging module $\mathrm{HC}$ - SR04 provides $2 \mathrm{~cm}$ $-400 \mathrm{~cm}$ non-contact measurement function. The ranging accuracy can reach to $3 \mathrm{~mm}$. The modules includes ultrasonic transmitters, receiver and control circuit[5]. The basic operation of the sensor is as following:

- Using IO trigger for at least 10us high level signal.

- The module automatically sends eight $40 \mathrm{kHz}$ and detect whether there is a pulse signal back.

- If the signal back, through high level, time of high output IO duration is the time from sending ultrasonic to returning.
Distance $=($ high level time $\times$ velocity of sound $(340 \mathrm{M} / \mathrm{S}) / 2$.

\subsection{Arduino UNO board}

Arduino Uno is a "microcontroller board based on the ATmega328P. It has 14 digital input/output pins (of which 6 can be used as PWM outputs), 6 analog inputs, a $16 \mathrm{MHz}$ quartz crystal, a USB connection, a power jack, an ICSP header and a reset button"[6]. The technical specifications of the board which taken from its data sheet is shown in table1.

Table1: Technical specifications of Arduino UNO board

\begin{tabular}{|l|l|}
\hline Microcontroller & ATmega328P \\
\hline Operating Voltage & $5 \mathrm{~V}$ \\
\hline $\begin{array}{l}\text { Input Voltage } \\
\text { (recommended) }\end{array}$ & $7-12 \mathrm{~V}$ \\
\hline Input Voltage (limit) & $6-20 \mathrm{~V}$ \\
\hline Digital I/O Pins & $\begin{array}{l}14 \text { (of which 6 provide } \\
\text { PWM output) }\end{array}$ \\
\hline PWM Digital I/O Pins & 6 \\
\hline Analog Input Pins & 6 \\
\hline DC Current per I/O Pin & $20 \mathrm{~mA}$ \\
\hline $\begin{array}{l}\text { DC Current for 3.3V } \\
\text { Pin }\end{array}$ & $50 \mathrm{~mA}$ \\
\hline Flash Memory & $\begin{array}{l}32 \mathrm{~KB}(\mathrm{ATmega} 328 \mathrm{P}) \\
\text { of which } 0.5 \mathrm{~KB} \text { used by } \\
\text { bootloader }\end{array}$ \\
\hline SRAM & $2 \mathrm{~KB}(\mathrm{ATmega328P})$ \\
\hline EEPROM & $1 \mathrm{~KB}(\mathrm{ATmega328 \textrm {P }})$ \\
\hline Clock Speed & $16 \mathrm{MHz}$ \\
\hline LED_BUILTIN & 13 \\
\hline
\end{tabular}




\begin{tabular}{|l|l|}
\hline Length & $68.6 \mathrm{~mm}$ \\
\hline Width & $53.4 \mathrm{~mm}$ \\
\hline Weight & $25 \mathrm{~g}$ \\
\hline
\end{tabular}

\subsection{Water Pump (Rio Plus Aqua Pump)}

The pump provides versatile water pump system designed with high efficiency and reliability at lower cost. The pump used here has capacity of pumping 262 litres per hour[7].

\subsection{Relay Circuit}

This component is controlled by the Arduino UNO board based on the measured water level signals received back by ultrasonic sensors [8].

\section{PROGRAM FLOWCHART}

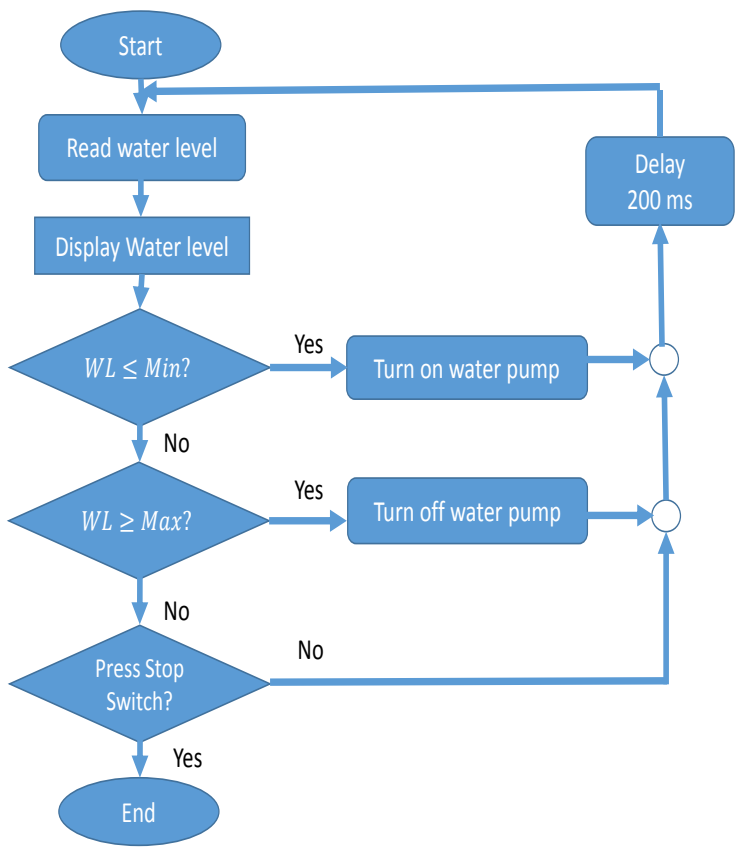

Figure 3Program flowchart that shows process of monitoring and controlling

\section{Flowchart Description}

- The overhead tank has two levels, maximum and minimum.

- Ultra-sonic sensors are used to continuously detect the level of water (WL) in the water tank.

- Via Arduino UNO, LabVIEW monitors the water level and shows the current level of the water.
- If $\mathrm{WL} \leq \mathrm{Min}$, the relay will turn the water pump on to pump water into the water tank. And the water level will also be monitored.

- If no, the second scenario is $\mathrm{WL} \geq \mathrm{Max}$, the Relay will be instructed to turn off the water pump.

- If none of the above conditions achieved, the program will be continued in monitoring the water level until a predefined condition will be achieved.

\section{LABVIEW SYSTEM DESIGN SOFTWARE}

"LabVIEW is an integrated development environment designed specifically for engineers and scientists. Native to LabVIEW is a graphical programming language that uses a dataflow model instead of sequential lines of text code, empowering us to write functional code using a visual layout that resembles our thought process"[9].

\subsection{The Front Panel}

Figure 4 shows the front panel of the labVIEW program written to control the ciruit. In this front panel indicators and controlling signals are existed. The water level history chart will show the continuos instant values of the detect water level wave by the sensors over a period of time. In addition, the water level tank indiator indicated the current discrete detected level of the water in the overhead tank.

The two Boolean buttons show the states of the water pump. The two round knobs are used to adjust the minimum and maximum predefined water levels in LabVIEW program so that when limit reached out, the relay circuit will correspondly be getting commands to turn $\mathrm{ON}$ and OFF the water pump.

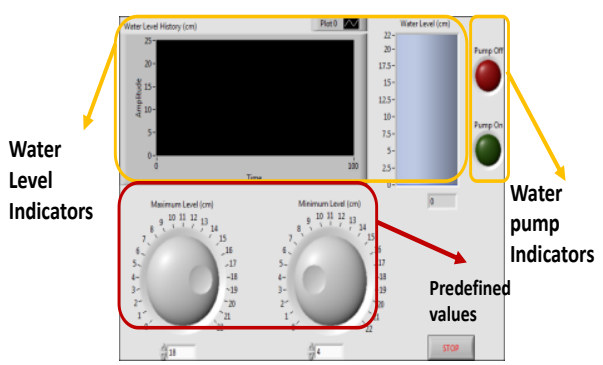

Figure 4Front panel of the LabVIEW program 


\subsection{The Block Diagram}

\subsubsection{Block Diagram Description}

1 Initial Block: This block is responsible to initialise a connection between Arduino UNO board and LabVIEW through giving information about the USB port, Baud rate and board type which is Arduino UNO.
2 Flat Sequence Structure: This structure is used to prepare the Water pump off via the relay circuit before the program starts running. Within this structure digital write pin is employed to follow the structure's function.

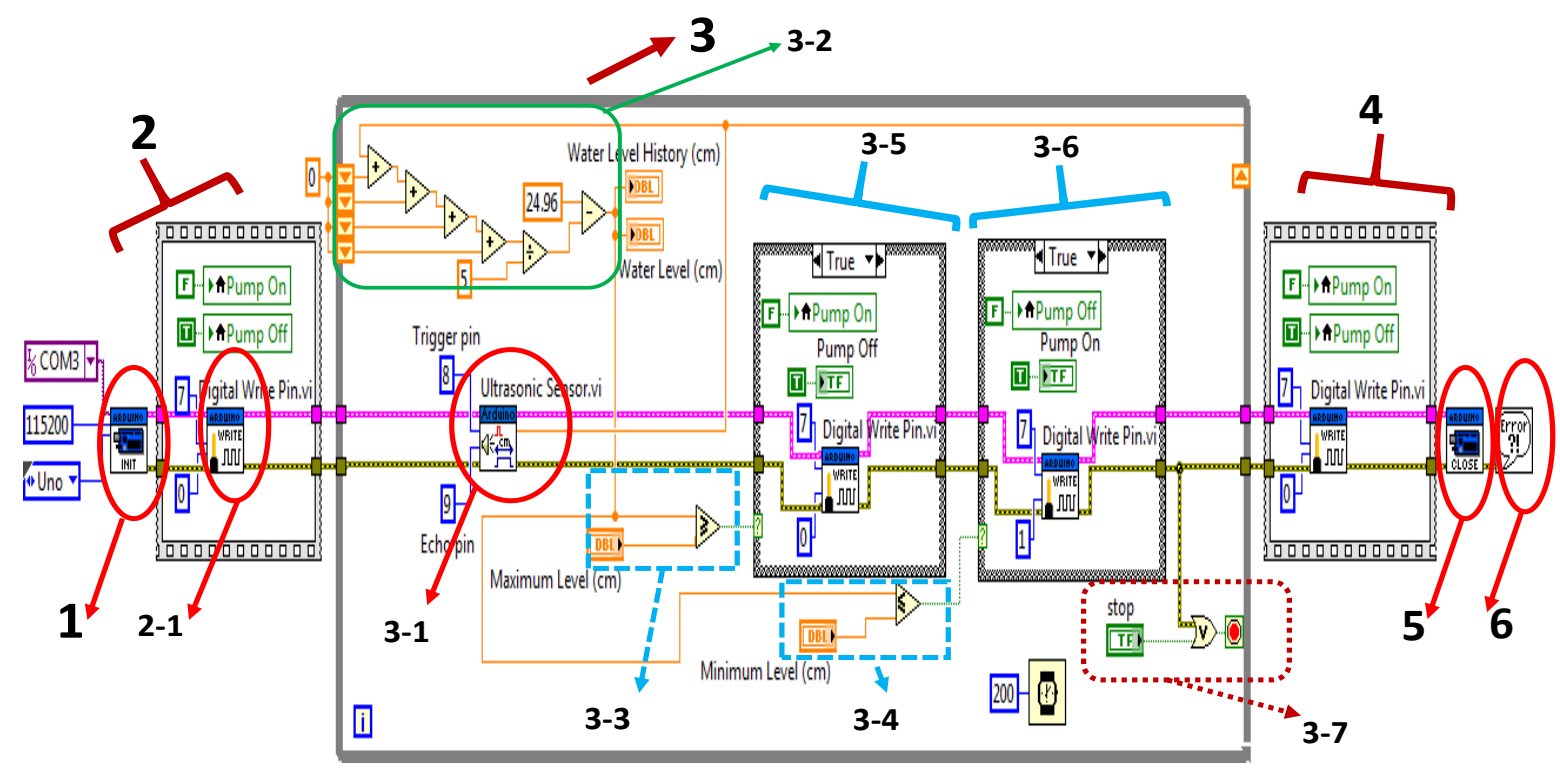

Figure 5Description of the LabVIEW block diagram

2-1 Digital Write Pin: This block is used to send the turning off data which is binary 0 (0 volt) to pin number 7 on Arduino UNO board to instruct the relay to be open circuit.

3 While loop: This block includes the main program that is responsible to detect and control the overhead water level automatically. And the Loop executes every 200 ms.

3-1 Ultrasonic Sensor Block: This block is mainly responsible to detect and measure the water level in the overhead tank by setting trigger pin and echo pin of the sensor to pin number 8 and 9 on the Arduino board respectively.

3-2 Moving Average Filter: This filter is employed to filter out the noise and distortions from the actual measured distance or the water surface level.

3-3 Comparator and 3-4 Comparator: These comparators are used to compare the actual measured water level to a predefined maximum and minimum levels in the programme. If specific conditions are met, the program will automate the water pump ON and OFF.
3-5 Case Structure: This block is directly connected to (3-3 comparator), and has two cases true or false. If actual measured water level in the overhead tank is larger or equal to the preassigned maximum water level, then the case is true and the case structure will send turn off command to the relay circuit to turn off the water pump, else nothing to do.

3-6 Case Structure: This block has the same functionality as (3-5 Case Structure). It is connected to the (3-4 comparator) and when minimum water level condition is reached. The true case of this structure will command the relay circuit to turn on the water pump to pump up water from down reservoir to the overhead tank.

3-7 Stop Button: Through this section, the program can be stopped whenever an error is occurring or the program is manually stopped.

4 Flat Sequence Structure: The main function of this structure is to command the relay circuit to turn off the water pump whenever an error occurs or the program will be manually stopped. 
5 Close Block: This block closes the active connection of LabVIEW to Arduino UNO board.

6 Simple Error Handler: This block shows an automatic error message when an error happens in the program. The description of the error will also be presented in this block.

\subsubsection{Ultrasonic Sensor Block Diagram}

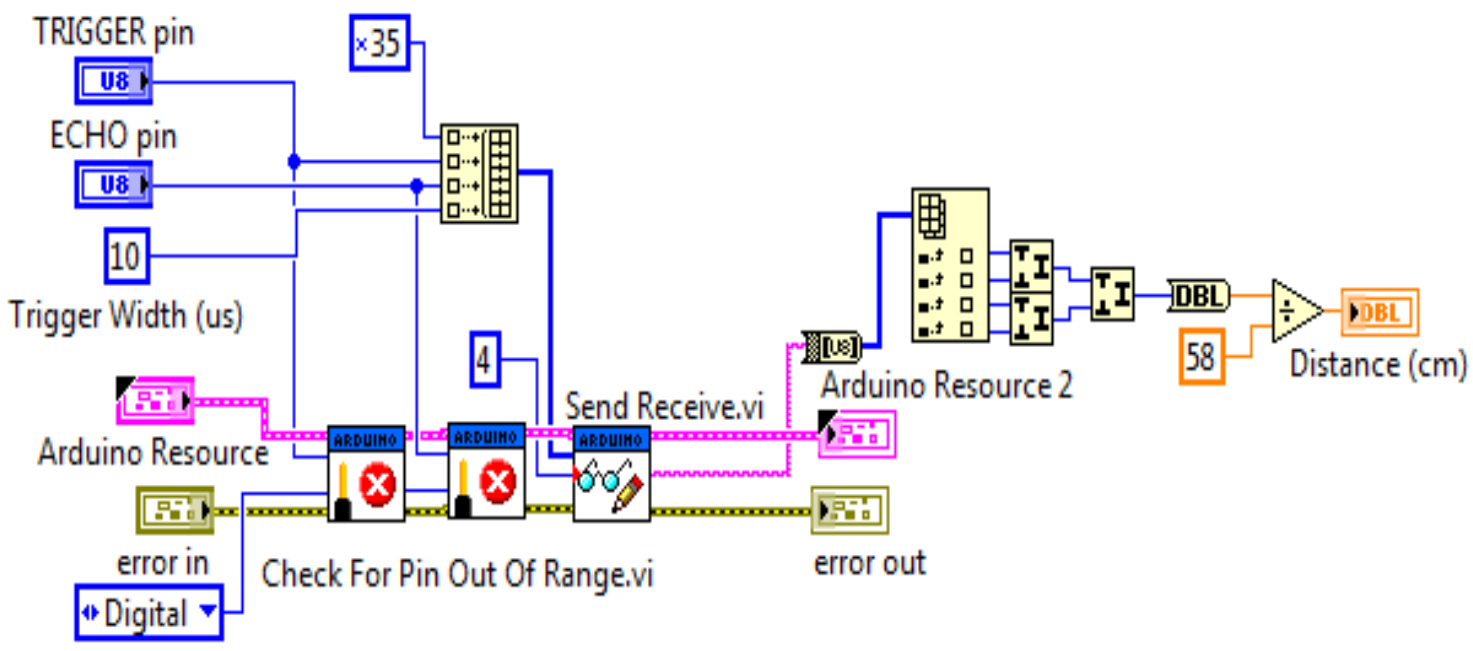

Figure 6Description of the Ultrasonic Sub VI block diagram in LabVIEW

\section{RESULTS AND DISCUSSIONS}

Figure 7 shows the photo of the system prototype when tested to get real measurements. The data shown in table 2 is representing desired and actual water level values in the overhead tank. The difference between the actual and desired values is expressed as absolute error. As it can be seen from the table, the maximum error occurred is $2.3 \mathrm{~mm}$, this shows that the system to a great extent is accurate in readings. The graphical presentations of relationship between desired and actual water level values for the prototype as well as the absolute error curve is shown in figure 8 and figure 9 respectively. As it can be noticed the curve between the actual values and desired values is almost linear. In addition, the absolute error stays below $2.3 \mathrm{~mm}$ during real measurements.

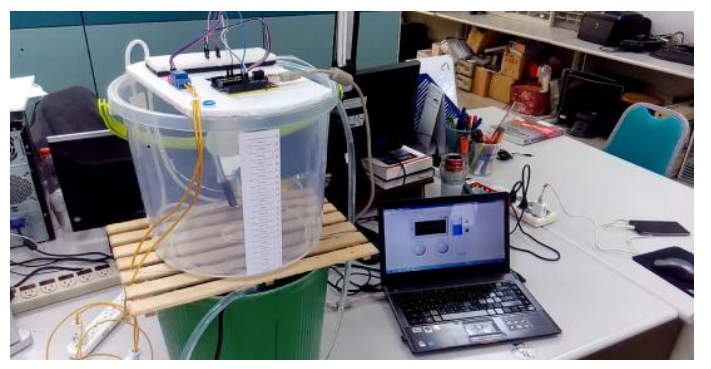

Figure 7Photo of the prototype during measurements

Table 2: Measured actual water level and calculated absolute error

\begin{tabular}{ccc}
\hline $\begin{array}{c}\text { Desired } \\
\text { Water Level } \\
(\mathbf{c m})\end{array}$ & $\begin{array}{c}\text { Actual Water } \\
\text { Level }(\mathbf{c m})\end{array}$ & $\begin{array}{c}\text { Absolute Error } \\
(\mathbf{c m})\end{array}$ \\
2 & 1.8744 & 0.1256 \\
2.5 & 2.3774 & 0.1226 \\
3 & 2.8637 & 0.1363 \\
3.5 & 3.3685 & 0.1315 \\
4 & 3.8637 & 0.1363 \\
4.5 & 4.3981 & 0.1019 \\
5 & 4.8464 & 0.1536 \\
5.5 & 5.3706 & 0.1294 \\
6 & 5.8843 & 0.1157 \\
\hline
\end{tabular}




\begin{tabular}{|c|c|c|}
\hline 6.5 & 6.3671 & 0.1329 \\
\hline 7 & 6.8637 & 0.1363 \\
\hline 7.5 & 7.3492 & 0.1508 \\
\hline 8 & 7.8671 & 0.1329 \\
\hline 8.5 & 8.3706 & 0.1294 \\
\hline 9 & 8.8995 & 0.1005 \\
\hline 9.5 & 9.4016 & 0.0984 \\
\hline 10 & 9.9292 & 0.0708 \\
\hline 10.5 & 10.4706 & 0.0294 \\
\hline 11 & 11.0395 & 0.0395 \\
\hline 11.5 & 11.5435 & 0.0435 \\
\hline 12 & 12.0537 & 0.0537 \\
\hline 12.5 & 12.5464 & 0.0464 \\
\hline 13 & 13.1154 & 0.1154 \\
\hline 13.5 & 13.6395 & 0.1395 \\
\hline 14 & 14.2119 & 0.2119 \\
\hline 14.5 & 14.6878 & 0.1878 \\
\hline 15 & 15.1464 & 0.1464 \\
\hline 15.5 & 15.6464 & 0.1464 \\
\hline 16 & 16.2326 & 0.2326 \\
\hline 16.5 & 16.6981 & 0.1981 \\
\hline 17 & 17.1119 & 0.1119 \\
\hline 17.5 & 17.5602 & 0.0602 \\
\hline 18 & 18.0808 & 0.0808 \\
\hline 18.5 & 18.6119 & 0.1119 \\
\hline 19 & 19.1809 & 0.1809 \\
\hline 19.5 & 19.5395 & 0.0395 \\
\hline 20 & 20.0429 & 0.0429 \\
\hline
\end{tabular}

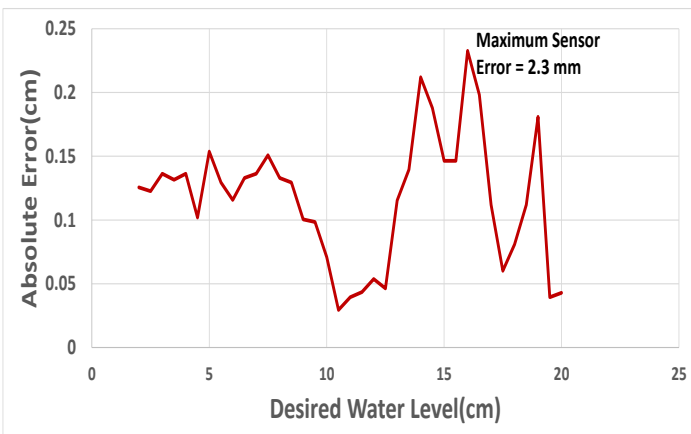

Figure 9Absolute error graph

\section{CONSTRAINTS}

During conducting the experiment it has been observed that more accurate and better performance results can be achieved and obtained is the following constrains are taken into considerations.

- The ultrasonic sensor measuring angle is 15 degree, due to this limitation for the prototype, larger size of bucket must be used to avoid destructive interferences in the received signal to increase the accuracy of measurement.

- A smooth and surface level for installing water tanks is needed, this is also one way to avoid destructive interferences among the received back signals to eliminate error.

- Suitable water pump and water pipes with specific capacities should be chosen with respect to the size of the overhead tank to allow enough time to the program to do calculations.

\section{CONCLUSION}

The prototype has been programed and implemented successfully. Good accuracy is achieved in detecting the water level, and controlling system when introduced constraints are taken into consideration. Linearity in the relationship curve between desired and actual water level values achieved. Staying absolute error below $2.3 \mathrm{~mm}$ maximum is the marker of the system accuracy.

\section{REFERENCES}

[1] E. V. Ebere and O. O. Francisca, "Microcontroller based Automatic Water level Control System," Int. J. Innov. Res. Comput. Commun. Eng., vol. 1, no. 6, pp. 
1390-1396, 2013.

[2] S. Pudasaini, A. Pathak, S. Dhakal, and M. Paudel, "Automatic Water Level Controller with Short Messaging Service (SMS) Notification," Int. J. Sci. Res. Publ., vol. 4, no. 9, pp. 518-521, 2014.

[3] A. A. M. Eltaieb and Z. J. Min, "Automatic Water Level Control System," Int. J. Sci. Res., vol. 4, no. 12, pp. 1505-1509, 2015.

[4] S. M. K. Reza et al., "Microcontroller Based Automated Water Level Sensing and Controlling: Design and Implementation Issue," World Congr. Eng. Comput. Sci. Vols 1 2, vol. I, pp. 220-224, 2010.

[5] "Ultrasonic Sensor - HC-SR04 - SEN-13959 SparkFun Electronics." [Online]. Available: https://www.sparkfun.com/products/13959. [Accessed: 18-Mar-2017].

[6] A. Store, "Arduino UNO Rev3," online, 2014. [Online]. Available: https://store.arduino.cc/usa/arduino-uno-rev3. [Accessed: 22-Mar-2017].

[7] "TAAM, Aquarium Products." [Online]. Available: http://www.riopump.net/products_pumps/Rioplus_de sc.html. [Accessed: 26-Mar-2017].

[8] "SRD-05VDC-SL-C Datasheet PDF - SRD RELAY - SONGLE." [Online]. Available: http://www.datasheetcafe.com/srd-05vdc-sl-cdatasheet-pdf/. [Accessed: 26-Mar-2017].

[9] N. Instruments, “Образовательные, научные и инженерные приложения в среде LabVIEW и технологии National Instruments," 2010. 